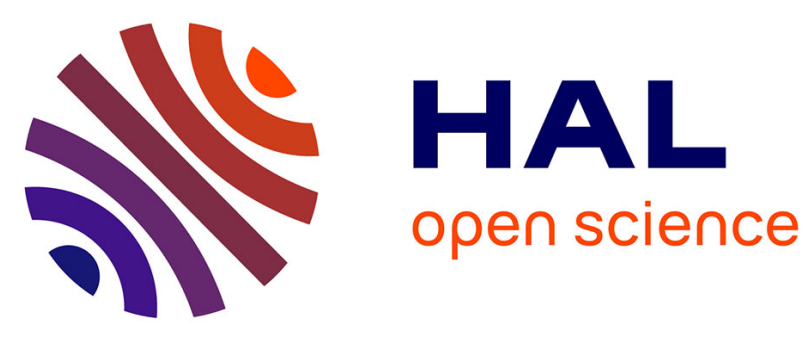

\title{
Genetic variants within miR-126 and miR-335 are not associated with breast cancer risk
}

Rongxi Yang, Michelle Dick, Frederik Marme, Andreas Schneeweiss, Anne

Langheinz, Kari Hemminki, Christian Sutter, Peter Bugert, Barbara

Wappenschmidt, Raymonda Varon, et al.

\section{To cite this version:}

Rongxi Yang, Michelle Dick, Frederik Marme, Andreas Schneeweiss, Anne Langheinz, et al.. Genetic variants within miR-126 and miR-335 are not associated with breast cancer risk. Breast Cancer Research and Treatment, 2010, 127 (2), pp.549-554. 10.1007/s10549-010-1244-x . hal-00594474

\section{HAL Id: hal-00594474 \\ https://hal.science/hal-00594474}

Submitted on 20 May 2011

HAL is a multi-disciplinary open access archive for the deposit and dissemination of scientific research documents, whether they are published or not. The documents may come from teaching and research institutions in France or abroad, or from public or private research centers.
L'archive ouverte pluridisciplinaire HAL, est destinée au dépôt et à la diffusion de documents scientifiques de niveau recherche, publiés ou non, émanant des établissements d'enseignement et de recherche français ou étrangers, des laboratoires publics ou privés. 


\section{Genetic variants within miR-126 and miR-335 are not associated with breast cancer risk}

Rongxi Yang ${ }^{1,2} *$, Michelle Dick ${ }^{1,2} *$, Frederik Marme ${ }^{1}$, Andreas Schneeweiss ${ }^{1}$, Anne Langheinz $^{1,2}$, Kari Hemminki ${ }^{3,4}$, Christian Sutter ${ }^{5}$, Peter Bugert ${ }^{6}$, Barbara Wappenschmidt ${ }^{7}$, Raymonda $\operatorname{Varon}^{8}$, Sarah Schott ${ }^{1}$, Bernhard H. F. Weber ${ }^{9}$, Dieter Niederacher ${ }^{10}$, Norbert Arnold $^{11}$, Alfons Meindl ${ }^{12}$, Claus R. Bartram ${ }^{5}$, Rita K. Schmutzler ${ }^{7}$, Heiko Müller ${ }^{13}$, Volker Arndt $^{13}$, Hermann Brenner ${ }^{13}$, Christof Sohn ${ }^{1}$ and Barbara Burwinkel ${ }^{1,2}$

${ }^{1}$ Division Molecular Biology of Breast Cancer, Department of Gynecology and Obstetrics, University of Heidelberg, 69120 Heidelberg, Germany

${ }^{2}$ Helmholtz-University Group Molecular Epidemiology, German Cancer Research Center (DKFZ), Im Neuenheimer Feld 581, 69120 Heidelberg, Germany

${ }^{3}$ Division of Molecular Genetic Epidemiology, German Cancer Research Center (DKFZ), Heidelberg, Germany, Im Neuenheimer Feld 580, 69120 Heidelberg, Germany

${ }^{4}$ Department of Biosciences at Novum, Karolinska Institute, 14157 Huddinge, Sweden

${ }^{5}$ Institute of Human Genetics, University of Heidelberg, 69120 Heidelberg, Germany

${ }^{6}$ Institute of Transfusion Medicine and Immunology, Red Cross Blood Service of Baden-WürttembergHessen, University of Heidelberg, Medical Faculty of Mannheim, Mannheim, Germany

${ }^{7}$ Division of Molecular Gynaeco-Oncology, Department of Gynaecology and Obstetrics, Clinical Center University of Cologne, 50931 Cologne, Germany

${ }^{8}$ Institute of Human Genetics, Charité, Humboldt University, Augustenburger Platz 1, 13353 Berlin, Germany

${ }^{9}$ Institute of Human Genetics, University of Regensburg, 93053, Regensburg, Germany

${ }^{10}$ Division of Molecular Genetics, Department of Gynaecology and Obstetrics, Clinical Center University of Düsseldorf, 40225, Düsseldorf, Germany

${ }^{11}$ Division of Oncology, Department of Gynaecology and Obstetrics, University Hospital SchleswigHolstein, 24105 Kiel, Germany

${ }^{12}$ Department of Gynaecology and Obstetrics, Klinikum rechts der Isar, Technical University of Munich, 81675 Munich, Germany

${ }^{13}$ Division of Clinical Epidemiology and Aging Research, German Cancer Research Center, Im Neuenheimer Feld 280, 69120 Heidelberg, Germany

* These two authors contributed equally to this study. 
Please address correspondence to: Rongxi Yang

Helmholtz-University Group Molecular Epidemiology, German Cancer Research Center (DKFZ), Im Neuenheimer Feld 581, 69120 Heidelberg, Germany

Tel: +49-6221-568403

Fax: +49-6221-568242

E-mail: r.yang@dkfz.de 


\begin{abstract}
MicroRNAs (miRNAs) are 20 22 nt non-coding RNAs which promote the degradation of target mRNAs or repression of the translation of mRNAs by sequence specific targeting. Many miRNAs are considered as oncogenes or tumor suppressors. MiR-126 and miR-335 play roles in the suppression of breast cancer metastasis by inhibiting tumor growth, proliferation and cell invasion. The effects of SNPs within the two miRNAs are still unknown. In our study, we analysed two SNPs, rs4636297 within miR-126 and rs41272366 within miR335 , in three study populations for a putative association with breast cancer risk. We compared the genotype and allele frequencies of rs4636297and rs41272366 in 2854 cases versus 3188 controls of the three study populations independently and combined. None of the performed analyses showed statistically significant results. In conclusion, our data suggest that the two genetic variants within miR-126 and miR-335 are not associated with breast cancer risk.
\end{abstract}




\section{Introduction}

MicroRNAs are a cluster of small endogenous non-coding RNAs (20 22 nt) that can bind to the 3' untranslated region of their target messenger RNAs (mRNAs) and lead to degradation or translation suppression of mRNAs [1,2]. A single miRNA can repress the expression of hundreds of proteins [3]. MiRNAs are involved in the regulation of several cellular pathways including pathways important for cancer development such as immune system regulation, haematopoiesis, angiogenesis, cell proliferation, differentiation and apoptosis [4-9]. Elevated or decreased expression of miRNAs has been found in various tumor types including breast cancer $[10,11]$. Some miRNAs thereby have been considered as tumor suppressors or oncogenes [12-14]. They have been shown to be involved in cancer initiation and progression by suppressing the expression of cancer-related genes [15]. Notably, miRNA processing defects also increase the risk of tumorigenesis [16]. Furthermore, miRNA expression profiles can be molecular markers for cancer diagnosis and therapy $[17,18]$.

Breast cancer accounts for one fourth of all female cancers, making it by far the most common cancer in women worldwide, and after lung cancer the second most frequent cancer (10.4\% of all cancers) in the world [19]. Taking the U.S. female population as an example, approximately one in eight women will develop breast cancer at some time in their lives [20]. Unfavourable combinations of polymorphic genetic variants in low-penetrance susceptibility genes contribute to breast cancer risk. Most of these susceptibility genes have not been discovered yet [21, 22].

Tavazoie and co-workers reported miR-126 and miR-335 as metastasis suppressor genes. They found that restoring the expression of miR-126 and miR-335 in malignant breast cancer cells can suppress the metastasis to lung and bone [23]. MiR-126 inhibits the tumour growth and proliferation, whereas miR-335 suppresses metastatic cell invasion [23]. Mutations and single nucleotide polymorphisms (SNPs) in miRNAs or miRNA target sites have been shown to be associated with the risk of various cancers [15, 24-28]. Some SNPs located in the miRNAs or their flanking regions are reported to have potential impact on the maturation of miRNAs [29]. In order to study the potential association of SNPs within miR-126 and miR335 with breast cancer risk, we sequenced the miR-126 and miR-335 and their flanking regions $( \pm 200 \mathrm{bp})$ and verified the presence of three SNPs, rs4636297, rs3807348 and rs41272366. In our previous study, rs3807348 was genotyped, whereas rs4636297 and 
rs41272366 were not investigated as they could not be analysed by the TaqMan genotyping assay [27]. Here, we have investigated rs4636297 and rs41272366 by the MALDI-TOF mass spectrometry (Sequenom, CA) in three different study populations for an association with breast cancer risk.

\section{Materials and methods}

\section{Study populations}

\section{The familial breast cancer study cohort of the German Consortium of Hereditary Breast and Ovarian Cancer (GC-HBOC):}

Genotyping was performed on genomic DNA of $B R C A 1 / 2$ mutation-negative index patients from 1217 German breast cancer families, comprising a subset of 115 bilateral breast cancer cases, versus 1422 unrelated healthy German women. BRCAl/2 mutation-negativity in the unrelated breast cancer cases had been tested by applying mutational screening of all exons by denaturing high performance liquid chromatography (DHPLC), and followed by direct sequencing of conspicuous exons [30]. Breast cancer samples were collected during the years 1997-2007 by seven centres of the GC-HBOC (centres of Heidelberg, Wuerzburg, Cologne, Kiel, Duesseldorf, Munich and Berlin, see authors' affiliations). German index patients were first diagnosed with breast cancer and then referred to a family registry. All the samples from the breast cancer patients were obtained around the diagnosis. The informed consent for the study was given to all breast cancer patients.

The control population included unrelated healthy female blood donors collected by the German Red Cross Blood Service of Baden-Wuerttemberg-Hessia and the Institute of Transfusion Medicine and Immunology (Mannheim), sharing the same ethnic background with the breast cancer patients (Caucasian/German population). All control individuals were healthy when donating their blood. None of the control individuals had a reported family history of breast cancer. Age distributions in controls and breast cancer cases were similar (controls: mean age 45.8 years old, median age 49 years old, range from 18 to 68 years old; cases: mean age 46.2 years old, median age 46 years old, range from 19 to 87 years old). The controls were randomly selected during the years 2004-2007 for this study and no further inclusion criteria were applied during recruitment. The study was approved by the Ethics Committee of the University of Heidelberg (Heidelberg, Germany). According to the German 
guidelines for blood donation, all blood donors were examined by a standard questionnaire. The informed consent for the study was given to all participants.

\section{The Breast Cancer study of the University Clinic Heidelberg (BSUCH):}

Genotyping was performed on genomic DNA of from 1115 German breast cancer patients recruited at the Department of Obstetrics and Gynecology of the University Hospital in Heidelberg, Germany, between 2006 and 2009. All patients gave informed written consent. The study was approved by the Ethics Committee of the University of Heidelberg (Heidelberg, Germany) and all patients gave informed written consent. The control population included 1236 unrelated healthy female blood donors collected by the German Red Cross Blood Service of Baden-Wuerttemberg-Hessia and Institute of Transfusion Medicine and Immunology (Mannheim), as described above. The controls were randomly selected during the years 2006-2008 for this study. Age distributions in controls and breast cancer cases were similar (controls: mean age 52.5 years old, median age 56 years old, range from 30 to 69 years old; cases: mean age 54.8 years old, median age 56 years old, range from 21 to 88 years old).

\section{The ESTHER/VERDI Study:}

Genotyping was performed on genomic DNA of from 513 German breast cancer patients, recruited in the German Federal state of Saarland between 1997 and 2003, versus 520 unrelated healthy German female controls recruited from the Saarland's general population in 2000-2002. Recruitment of cases was performed by all hospitals providing primary treatment for breast cancer patients in Saarland as a part of the VERDI study [31] and the ESTHER II study [32]. $94 \%$ of the samples from the breast cancer patients were obtained after the surgery. Controls were recruited by general practitioners in Saarland during a general health screening examination in the context of the ESTHER I study [33]. For this analysis, 520 women, frequency matched by age to the cases, were randomly selected from ESTHER I. The studies were approved by the Ethics Committee of the University of Heidelberg (Heidelberg, Germany) and of the Medical Association of Saarland (Saarbruecken, Germany). Informed consent was obtained in each case. Age distributions in controls and breast cancer cases were similar (controls: mean age 62.3 years old, median age 63 years old, range from 49 to 75 years old; cases: mean age 60.5 years old, median age 62 years old, range from 30 to 79 years old).

\section{SNP verification and sequencing}


In order to verify annotated SNPs from the SNP database (NCBI) and to identify potential new SNPs, miR126 and miR335 genes, including pre-miRNAs and about \pm 200 bp flanking regions, were amplified by standard PCR (in order to unfold the secondary structure of miRNAs, $5 \%$ DMSO was added to the PCR buffer). PCR products were purified with the ExoSAP-IT purification kit (USB Corp.) and were sequenced in one of the directions by the 3130XL Genetic Analyzer (Applied Biosystems). Sequencing results were analyzed by the Sequencing Analysis 5.2 software (Applied Biosystems). As a result, three SNPs, rs4636297, rs3807348 and rs41272366, were verified in these segments.

\section{Genotyping by MALDI-TOF mass spectrometry}

We investigated the genotype frequencies of rs4636297 and rs41272366 in this study by the MALDI-TOF mass spectrometry (Sequenom MassArray, San Diego, CA). rs3807348 has already been examined in our previous study by a TaqMan genotyping assay.

Assays were designed by the Sequenom Assay Design software v2.0.7.0. The whole process followed the protocol of multiplexed genotyping reactions using iPLEX Gold for MassArray. At the primary PCR step, DNA was amplified under following conditions: $95^{\circ} \mathrm{C}$ for 2 min, then 45 cycles of $\left(95^{\circ} \mathrm{C}\right.$ for $30 \mathrm{~s}, 56{ }^{\circ} \mathrm{C}$ for $30 \mathrm{~s}$, and $72{ }^{\circ} \mathrm{C}$ for $\left.1 \mathrm{~min}\right)$, and a further extension at $72{ }^{\circ} \mathrm{C}$ for 5 min before storage at $4{ }^{\circ} \mathrm{C}$. After purification by the SAP kit, the PCR products were treated by the extend reaction with iPLEX Extend Cocktail (following the instruction of Sequenom). The microplate was thermocycled as follows: $94{ }^{\circ} \mathrm{C}$ for $30 \mathrm{~s}$, then 50 cycles of $\left(94{ }^{\circ} \mathrm{C}\right.$ for $5 \mathrm{~s}$ then 4 cycles of $\left(52{ }^{\circ} \mathrm{C}\right.$ for $5 \mathrm{~s}, 80{ }^{\circ} \mathrm{C}$ for $5 \mathrm{~s}$ )), a final extension at $72{ }^{\circ} \mathrm{C}$ for 3 min and stored at $4{ }^{\circ} \mathrm{C}$. After cleaned by CLEAN Resin, the samples were dispensed to a 384 SpectroCHIP by the Nanodispenser. The chip was analyzed by a Bruker Autoflex Mass Spectrometer system. Data were collected by the SpectroACQUIRE v3.3.1.3 software and visualised by the MassArray Typer v4.0 TyperAnalyzer software. Sequences of primers are available upon request.

\section{Statistical analysis}


The Hardy-Weinberg equilibrium [32] test was applied using the chi-square 'goodness-of-fit' test offered as a tool by the Institute of Human Genetics, Technical University Munich, Munich, Germany (http://ihg.gsf.de/cgi-bin/hw/hwa1.pl). Genotype-specific odds ratios (OR), $95 \%$ confidence intervals (CI) and $P$ values were computed by unconditional logistic regression with SAS version 9.1 (SAS Institute Inc., Cary, NC). Age, treated as a continuous variable was included in the regression as a covariate. Study population, treated as a discrete variable was included in the regression as a covariate. $P$ values were calculated using twosided chi-square test. The meta analysis was done by STATA 9.0. Power was calculated using the power and sample size calculation software PS version 2.1.31 (http://www.mc.vanderbilt.edu/prevmed/ps/index.htm) [34].

\section{Results}

We sequenced the DNA segments including the pre-miR-126, pre-miR-335 and their respective flanking regions $( \pm 200 \mathrm{bp}$ ) in more than 100 randomly chosen familial breast cancer cases. Using this approach three SNPs, rs4636297, rs3807348 and rs41272366, were verified in these segments. We were able to localize rs4636297 12 bp downstream of premiR-126 and rs41272366 20 bp downstream of pre-miR-335. Neither these two SNPs themselves nor their linkage SNPs $\left(\mathrm{r}^{2}>=0.8\right)$ had been analysed, so far, by the Cancer Genetic Markers of Susceptibility genome wide association study (CGEMS) (https://caintegrator.nci.nih.gov/cgems/browseSetup.do). The CGEMS is a whole-genome association study conducted by the National Cancer Institute (NCI) enterprise to identify breast cancer susceptibility genes using Illumina HumanHap550 assays on approximately 1200 breast cancer patients and 1200 controls. The additional two annotated SNP in pre-miR126 (not validated SNPs in dbSNP), rs34051017 and rs7030829, could not be verified in our sample set possibly due to wrong annotations or very low frequency.

Genotype analysis of the two SNPs was performed on genomic DNA of three breast cancer study populations (GC-HBOC, BSUCH, ESTHER/VERDI, see materials and methods). All of the samples previously genotyped by sequencing were re-genotyped by the MALDI-TOF mass spectrometry assay and attained a concordance rate of $100 \%$. The MALDI-TOF mass spectrometry genotyping results were validated by re-genotyping $5 \%$ of all the samples attaining concordance rates of $100 \%$ for all the investigated SNPs. Genotype distributions in controls and cases were consistent with the Hardy-Weinberg equilibrium [32]. 
The results were adjusted by age and studies with the SAS software version 9.1. Allele and genotype frequencies of rs4636297 and rs41272366 were comparable in breast cancer cases and controls. rs4636297: ([A] vs [G], OR $=1.01,95 \%$ CI 0.94-1.10, $P=0.73$; [GA] vs [GG], $\mathrm{OR}=1.01,95 \%$ CI 0.89-1.13, $P=0.93$; [AA] vs [GG], OR $=1.04,95 \%$ CI 0.87-1.23, $P=$ $0.69 ; P_{\text {trend }}=0.73$, Table 1) and rs41272366: ([A] vs [T], OR $=0.90,95 \%$ CI 0.69-1.17, $P=$ 0.43 ; [AT] vs $[\mathrm{TT}], \mathrm{OR}=0.88,95 \%$ CI $0.68-1.15, P=0.35 ; P_{\text {trend }}=0.43$, Table 1$)$, showing no association with breast cancer. The associations of the two SNPs with breast cancer were also analysed after stratification by age (age $<50$ years old and $>=50$ years old). However, none of the subgroups showed any significant association with breast cancer risk. The associations of the two SNPs with breast cancer were also analysed by single study population separately, but no significant association was observed. Meta-analysis did not indicate any between-study heterogeneity (for rs $4636297, P_{\text {heterogeneity }}=0.528$; for rs $41272366, P_{\text {heterogeneity }}$ $=0.275$, Figure 1$)$.

\section{Discussion}

More and more miRNAs are reported to be involved in the process of cancer [17]. MiR-126 and miR-335 have been reported as tumor suppressor genes [23]. They can inhibit tumor development and metastasis through negatively regulating a set of oncogenes. MiR-126 is involved in the angiogenesis. It binds to the 3' untranslated region of VEGF and subsequently negatively regulates the VEGF pathway [35, 36]. MiR-335 suppresses metastasis and migration through targeting the progenitor cell transcription factor SOX4 and extracellular matrix component tenascin C [23]. Expression of miR-126 and miR-335 is lost in the majority of primary breast tumors from patients who relapse, and the loss of expression of either miRNA is associated with poor distal metastasis-free survival [23].

Our work focused on the SNPs in the breast cancer related tumor suppressor genes, miR-126 and miR-335. As it has been reported that a mutation or a SNP in a miRNA gene can affect the transcription and/or procession of the pri- and pre-miRNAs [29], we have studied not only the SNPs in the pre-miRNAs but also vicinal SNPs in miRNA flanking regions (about \pm 200 bp). Given our sample size, we had a power of $80 \%(\alpha=0.05)$ to detect an OR of 1.18 for SNP rs4636297 and an OR of 0.66 for SNP rs41272366.

Both SNP rs4636297 and rs41272366 are located in the flanking region of pre-miRNAs, their effects on miRNA secondary structures and free energy is uncertain. We used the RNAfold 
program [37] (http://www.bioinfo.rpi.edu/applications/hybrid/) to predict the most stable secondary structure and free energy of both wild-types and variants. Comparing to the wildtype [G] allele, the [A] variant of rs4636297 has no effects on the secondary structure of premiR-126 itself, but effects the secondary structure of flanking region. Meanwhile, the free energy $\Delta \mathrm{G}$ is increased from $-52.7 \mathrm{kcal} / \mathrm{mol}$ of the wild-type to $-51.2 \mathrm{kcal} / \mathrm{mol}$ of the [A] allele variant. The effect of [A] allele in rs41272366 is similar and has no impact on the secondary structure of pre-miR-335. The [A] allele increases the free energy $\Delta \mathrm{G}$ from -54.6 $\mathrm{kcal} / \mathrm{mol}$ of the wild-type to $-54.2 \mathrm{kcal} / \mathrm{mol}$ of the variant. However, neither of the two SNPs affects the secondary structure of pre-miRNAs. Therefore, it is very likely that neither rs4636297 nor rs41272366 has effect on the miR-126 and miR-335 maturation and subsequently are not associated with breast cancer risk.

Recently, some polymorphisms in miRNAs have been reported to be associated with metastasis or survival of cancer patients [38-40]. Since miR-126 and miR-335 have been reported to be involved in tumor development, angiogenesis and distant metastasis, it is possible that these SNPs affect breast cancer prognosis such as metastasis and overall survival. Unfortunately, these data is not available for us from all study cohorts.

In conclusion, by investigating three study populations, we have not found an association between the SNPs rs4636297 and rs41272366 and breast cancer risk. All the three different studies consistently showed negative results. However, it would be interesting to investigate the association between these SNPs and breast cancer prognosis in the future.

\section{Acknowledgments}

This study was supported by the Dietmar-Hopp Foundation, the Helmholtz society and the German Cancer Research Center (DKFZ). The German breast cancer samples were collected within a project funded by the Deutsche Krebshilfe (Grant number: 107054). The VERDI study was supported by the Deutsche Krebshilfe (Grant number: M24/95/BRI). The ESTHER study was supported by a grant from the Baden-Württemberg Ministry of Science, Research and Arts. 


\section{References:}

1. Baek D, Villen J, Shin C, Camargo FD, Gygi SP, Bartel DP (2008) The impact of microRNAs on protein output. Nature 455:64-71.

2. Zeng Y, Yi R, Cullen BR (2003) MicroRNAs and small interfering RNAs can inhibit mRNA expression by similar mechanisms. Proc Natl Acad Sci U S A 100:9779-9784.

3. Selbach M, Schwanhausser B, Thierfelder N, Fang Z, Khanin R, Rajewsky N (2008) Widespread changes in protein synthesis induced by microRNAs. Nature 455:58-63.

4. Baltimore D, Boldin MP, O'Connell RM, Rao DS, Taganov KD (2008) MicroRNAs: new regulators of immune cell development and function. Nat Immunol 9:839-845.

5. Brennecke J, Hipfner DR, Stark A, Russell RB, Cohen SM (2003) bantam encodes a developmentally regulated microRNA that controls cell proliferation and regulates the proapoptotic gene hid in Drosophila. Cell 113:25-36.

6. Chang TC, Wentzel EA, Kent OA, Ramachandran K, Mullendore M, Lee KH, Feldmann G, Yamakuchi M, Ferlito M, Lowenstein CJ et al (2007) Transactivation of miR-34a by p53 broadly influences gene expression and promotes apoptosis. Mol Cell 26:745-752.

7. Calin GA, Cimmino A, Fabbri M, Ferracin M, Wojcik SE, Shimizu M, Taccioli C, Zanesi N, Garzon R, Aqeilan RI et al (2008) MiR-15a and miR-16-1 cluster functions in human leukemia. Proc Natl Acad Sci U S A 105:5166-5171.

8. Dews M, Homayouni A, Yu D, Murphy D, Sevignani C, Wentzel E, Furth EE, Lee WM, Enders GH, Mendell JT et al (2006) Augmentation of tumor angiogenesis by a Myc-activated microRNA cluster. Nat Genet 38:1060-1065.

9. Xiao C, Rajewsky K (2009) MicroRNA control in the immune system: basic principles. Cell 136:26-36.

10. Croce CM (2009) Causes and consequences of microRNA dysregulation in cancer. Nat Rev Genet 10:704-714.

11. Khoshnaw SM, Green AR, Powe DG, Ellis IO (2009) MicroRNA involvement in the pathogenesis and management of breast cancer. J Clin Pathol 62:422-428.

12. Johnson SM, Grosshans H, Shingara J, Byrom M, Jarvis R, Cheng A, Labourier E, Reinert KL, Brown D, Slack FJ (2005) RAS is regulated by the let-7 microRNA family. Cell 120:635-647. 
13. He L, Thomson JM, Hemann MT, Hernando-Monge E, Mu D, Goodson S, Powers S, Cordon-Cardo C, Lowe SW, Hannon GJ et al (2005) A microRNA polycistron as a potential human oncogene. Nature 435:828-833.

14. O'Donnell KA, Wentzel EA, Zeller KI, Dang CV, Mendell JT (2005) c-Myc-regulated microRNAs modulate E2F1 expression. Nature 435:839-843.

15. Esquela-Kerscher A, Slack FJ (2006) Oncomirs - microRNAs with a role in cancer. Nat Rev Cancer 6:259-269.

16. Kumar MS, Lu J, Mercer KL, Golub TR, Jacks T (2007) Impaired microRNA processing enhances cellular transformation and tumorigenesis. Nat Genet 39:673-677.

17. Calin GA, Croce CM (2006) MicroRNA signatures in human cancers. Nat Rev Cancer 6:857-866.

18. Lu J, Getz G, Miska EA, Alvarez-Saavedra E, Lamb J, Peck D, Sweet-Cordero A, Ebert BL, Mak RH, Ferrando AA et al (2005) MicroRNA expression profiles classify human cancers. Nature 435:834-838.

19. Key TJ, Verkasalo PK, Banks E (2001) Epidemiology of breast cancer. Lancet Oncol 2:133-140.

20. Belkora J, Moore DH, Hutton DW (2009) Assessing risk communication in breast cancer: are continuous measures of patient knowledge better than categorical? Patient Educ Couns 76:106-112.

21. Ponder BA (2001) Cancer genetics. Nature 411:336-341.

22. Pharoah PD, Antoniou A, Bobrow M, Zimmern RL, Easton DF, Ponder BA (2002) Polygenic susceptibility to breast cancer and implications for prevention. Nat Genet 31:33-36.

23. Tavazoie SF, Alarcon C, Oskarsson T, Padua D, Wang Q, Bos PD, Gerald WL, Massague J (2008) Endogenous human microRNAs that suppress breast cancer metastasis. Nature 451:147-152.

24. Duan R, Pak C, Jin P (2007) Single nucleotide polymorphism associated with mature miR-125a alters the processing of pri-miRNA. Hum Mol Genet 16:1124-1131.

25. Jazdzewski K, Murray EL, Franssila K, Jarzab B, Schoenberg DR, de la Chapelle A (2008) Common SNP in pre-miR-146a decreases mature miR expression and predisposes to papillary thyroid carcinoma. Proc Natl Acad Sci U S A 105:7269-7274.

26. Shen J, Ambrosone CB, DiCioccio RA, Odunsi K, Lele SB, Zhao H (2008) A functional polymorphism in the miR-146a gene and age of familial breast/ovarian cancer diagnosis. Carcinogenesis 29:1963-1966.

27. Yang R, Schlehe B, Hemminki K, Sutter C, Bugert P, Wappenschmidt B, Volkmann J, Varon R, Weber BH, Niederacher D et al (2010) A genetic variant in the pre-miR-27a 
oncogene is associated with a reduced familial breast cancer risk. Breast Cancer Res Treat 121:693-702.

28. Tchatchou S, Jung A, Hemminki K, Sutter C, Wappenschmidt B, Bugert P, Weber BH, Niederacher D, Arnold N, Varon-Mateeva R et al (2009) A variant affecting a putative miRNA target site in estrogen receptor (ESR) 1 is associated with breast cancer risk in premenopausal women. Carcinogenesis 30:59-64.

29. Wu M, Jolicoeur N, Li Z, Zhang L, Fortin Y, L'Abbe D, Yu Z, Shen SH (2008) Genetic variations of microRNAs in human cancer and their effects on the expression of miRNAs. Carcinogenesis 29:1710-1716.

30. Meindl A (2002) Comprehensive analysis of 989 patients with breast or ovarian cancer provides BRCA1 and BRCA2 mutation profiles and frequencies for the German population. Int J Cancer 97:472-480.

31. Arndt V, Sturmer T, Stegmaier C, Ziegler H, Becker A, Brenner H (2003) Provider delay among patients with breast cancer in Germany: a population-based study. J Clin Oncol 21:1440-1446.

32. Widschwendter M, Apostolidou S, Raum E, Rothenbacher D, Fiegl H, Menon U, Stegmaier C, Jacobs IJ, Brenner H (2008) Epigenotyping in peripheral blood cell DNA and breast cancer risk: a proof of principle study. PLoS One 3:e2656.

33. Gao L, Weck MN, Michel A, Pawlita M, Brenner H (2009) Association between chronic atrophic gastritis and serum antibodies to 15 Helicobacter pylori proteins measured by multiplex serology. Cancer Res 69:2973-2980.

34. Dupont WD, Plummer WD, Jr.(1998) Power and sample size calculations for studies involving linear regression. Control Clin Trials 19:589-601.

35. Fish JE, Santoro MM, Morton SU, Yu S, Yeh RF, Wythe JD, Ivey KN, Bruneau BG, Stainier DY, Srivastava D (2008) miR-126 regulates angiogenic signaling and vascular integrity. Dev Cell 15:272-284.

36. Liu B, Peng XC, Zheng XL, Wang J, Qin YW (2009) MiR-126 restoration downregulate VEGF and inhibit the growth of lung cancer cell lines in vitro and in vivo. Lung Cancer 66:169-75

37. Markham NR, Zuker M (2005) DINAMelt web server for nucleic acid melting prediction. Nucleic Acids Res 33:W577-581.

38. Christensen BC A-WM, Ouellet LG, Butler RA, Nelson HH, McClean MD, Marsit CJ, Kelsey KT (2010) Mature microRNA sequence polymorphism in MIR196A2 is associated with risk and prognosis of head and neck cancer. Clin Cancer Res 16:37133720 .

39. Lee HC, Kim JG, Chae YS, Sohn SK, Kang BW, Moon JH, Jeon SW, Lee MH, Lim KH, Park JY et al (2010) Prognostic impact of microRNA-related gene 
polymorphisms on survival of patients with colorectal cancer. J Cancer Res Clin Oncol 136:1073-1078.

40. Qi P, Dou TH, Geng L, Zhou FG, Gu X, Wang H, Gao CF (2010) Association of a variant in MIR 196A2 with susceptibility to hepatocellular carcinoma in male Chinese patients with chronic hepatitis B virus infection. Hum Immunol 71:621-626.

\section{Table}

Table 1. Genotype frequencies of rs4636297 and rs41272366 in the GC-HBOC, BSUCH and ESTHER study populations

\begin{tabular}{|c|c|c|c|c|c|c|}
\hline SNP & Genotypes & Case (\%) & Control (\%) & $\mathrm{OR}^{\mathrm{a}}$ & $95 \% \mathrm{CI}$ & $P^{b}$ \\
\hline \multirow{5}{*}{$\begin{array}{c}\mathrm{miR}-126 \\
\mathrm{rs} 4636297\end{array}$} & GG & 957 (39.5) & 1093 (39.9) & 1.000 & & \\
\hline & GA & $1136(46.9)$ & $1287(47.0)$ & 1.005 & $0.893-1.132$ & 0.9278 \\
\hline & AA & 327 (13.5) & $361(13.2)$ & 1.036 & $0.871-1.232$ & 0.6925 \\
\hline & {$[\mathrm{A}] \mathrm{vs}[\mathrm{G}]$} & & & 1.014 & 0.936-1.099 & 0.7327 \\
\hline & & & & & & $P_{\text {trend }}=0.7315$ \\
\hline \multirow{5}{*}{$\begin{array}{c}\mathrm{miR}-335 \\
\mathrm{rs} 41272366\end{array}$} & $\mathrm{TT}$ & 2283 (95.7) & $2580(95.2)$ & 1.000 & & \\
\hline & AT & $102(4.3)$ & $130(4.8)$ & 0.880 & $0.675-1.149$ & 0.3478 \\
\hline & AA & $1(0)$ & $0(0)$ & - & - & 0.9665 \\
\hline & {$[\mathrm{A}] \mathrm{vs}[\mathrm{T}]$} & & & 0.901 & $0.694-1.170$ & 0.4342 \\
\hline & & & & & & $P_{\text {trend }}=0.4307$ \\
\hline
\end{tabular}

a chi-square test for trend.

${ }^{\mathrm{b}}$ adjusted for age and study populations; all analyses done with SAS Version 9.1 Proc Logistic.

\section{Figure}




\begin{tabular}{|c|c|c|}
\hline Dominant model & OR $(95 \%$ CI $)$ & Weight $(\%)$ \\
\hline \multicolumn{3}{|l|}{ miR-126 rs4636297 GA/AA vs GG } \\
\hline GC-HBOC & $0.94(0.78,1.13)$ & 38.08 \\
\hline BSUCH & $1.08(0.91,1.28)$ & 42.18 \\
\hline ESTHER/VERDI & $1.01(0.78,1.30)$ & 19.74 \\
\hline Overall $\left(I^{2}=0.0 \%, P_{\text {heterogeniety }}=0.528\right)$ & $1.01(0.90,1.13)$ & 100.00 \\
\hline \multicolumn{3}{|l|}{ miR-335 rs41272366 AT/AA vs TT } \\
\hline GC-HBOC & $1.07(0.70,1.66)$ & 33.68 \\
\hline BSUCH & $0.92(0.62,1.37)$ & 44.43 \\
\hline ESTHER/VERDI & $0.57(0.30,1.08)$ & 21.89 \\
\hline Overall $\left(I^{2}=22.6 \%, P_{\text {heterogeniety }}=0.275\right)$ & $0.90(0.69,1.17)$ & 100.00 \\
\hline 0.30 & 3.34 & \\
\hline
\end{tabular}

Figure 1. ORs (log scale) of rs4636297 and rs41272355 for variant genotypes compared with the wild type genotypes in dominant genetic model. 